\title{
Analisis Nilai Visual Analog Scale (VAS) terhadap Penggunaan Analgetik pada Pasien pasca Seksio Sesarea di RSUD Kota Kendari
}

\author{
Agussalim Ali \\ Fakultas Kedokteran Universitas Halu Oleo \\ Email: agusanestesi0508@gmail.com
}

\begin{abstract}
Background: Sectio caesarean is one of choices for pregnant mother for her baby birth. The procedure of section caesarean has duration between 30-60 minutes. The procedure of section caesarean may induce moderate-severe pain in the surgical incision. This occurs because of the injury and the onset of inflammatory processes that secrete pain mediators, thus inducing pain. It must take the right analgesia choice. Research Purpose: This study was aimed at determining the value of Visual Analog Scale (VAS) on the use of analgesic in post-cesarean patients in RSUD Kendari. Method: Observational analytic design was used cross sectional approach. Dependent variable in this research were VAS T2, VAS T4 dan VAS T6 post operation. The independent variables of this study were analgesic (Ketorolak, Tramadol and Dexketoprofen). The location of this research was in RSUD Kendari with purposive sampling, 32 were covered samples. Data were obtained through interviews of VAS value with VAS card, blood pressure measurements with sphygmomanometer and stethoscope, pulse measurement with hold down arteri radialis and data from medical records. Kruskal-Wallis test was applied for data analysis, and if significant different followed by probability value/ sig $<0,05$ using Shapiro Wilk as normality test. After passing the inclusion, exclusion and drop out criteria, 32 patient samples were obtained. The number of patients for each analgesic were $10(n=10)$. This research showed the significancy value in the VAS $T 2=0,158$, the significancy value in the VAS T4=0,350 and the significancy value in the VAS T6 =0,679. Result: Result of the research showed that there were differences mean value between VAS T2, VAS T4 and VAS T6. Ketorolac $30 \mathrm{mg}$ was the lowest mean of VAS T2 between another analgetic, the value was 12,15. Dexketoprofen $50 \mathrm{mg}$ was the lowest mean of VAS T4 between another analgesc, the value was 13,85. Ketorolak $30 \mathrm{mg}$ was the lowest mean of VAS T6 between another analgetic, the value is 13,75. But there was no meaningful difference in statistical counting (sig >0,05) between Ketorolac $30 \mathrm{mg}$, Tramadol $100 \mathrm{mg}$ and Dexketoprofen 50 $m g$ in post-cesarean patients in RSUD Kendari.
\end{abstract}

Keywords: Section Cesarean, VAS, Ketorolak, Tramadol, Dexketoprofen

\section{PENDAHULUAN}

Seksio sesarea merupakan salah satu pilihan dari ibu hamil untuk menjalani kelahiran bayinya. Semua perempuan menginginkan persalinannya lancar dan melahirkan bayi dengan selamat. Sofian (2013) mengatakan seksio sesarea adalah suatu cara melahirkan janin dengan membuat sayatan pada dinding uterus melalui dinding depan perut untuk melahirkan janin dari dalam rahim. Prosedur seksio sesarea memiliki waktu kurang lebih 30-60 menit, sehingga banyak ibu hamil yang memilih kelahiran seksio sesarea dibandingkan kelahiran normal (Salfitriani dkk., 2012).

Trauma akibat insisi seksio sesarea menyebabkan terjadinya nyeri akut pasca operasi. Ibu hamil yang menjalani seksio sesarea memiliki angka kesakitan lebih tinggi dibandingkan ibu hamil yang menjalani persalinan normal. Menurut International Association for the Study of Pain (IASP), nyeri pasca operasi merupakan bagian dari nyeri nosiseptif yang mengaktifkan nosiseptor serabut alfa dan $\mathrm{C}$ yang menimbulkan reaksi neuroendokrin dan aktivasi simpatoadrenal menyebabkan perubahan pada sistem 
respirasi, sistem kardiovaskuler, dan psikologis (Agroff dkk., 2010).

Seksio sesarea umumnya menginduksi nyeri tingkat sedang sampai berat. Pengelolaan nyeri yang tidak efektif akan berlanjut menjadi nyeri kronik serta dapat menimbulkan dampak perubahan fisiologis yang membahayakan karena adanya respon dari endokrin, metabolik, dan inflamasi. Respon stres ini mengaktifkan sistem otonom yang dapat mengakibatkan berbagai kegagalan fungsi organ. Secara psikologis akan berdampak pada kecemasan, depresi, dan perasaan tidak puas. Oleh karena itu, diperlukan pengelolaan nyeri pasca operasi yang efektif dapat mengurangi risiko morbiditas dan mortalitas serta meningkatkan masa pemulihan sehingga dapat beraktifitas sehari-hari (Joshi dan Ogunnaike, 2005; Ismail dkk., 2012).

Pengelolaan nyeri terhadap pasien, tenaga medis memerlukan indikator dalam pemberian analgesik. VAS (Visual Analog Scale) dapat digunakan dalam menilai derajat nyeri yang dirasakan oleh pasien. VAS merupakan alat bantu yang paling sering digunakan untuk menilai intensitas nyeri pasien. Adapun kekurangan VAS yakni sulit untuk diinterpretasikan dan memerlukan ketelitian dalam menginterpretasikannya (Price, dkk., 2006; Pritaningrum, 2010).

Analgetik yang digunakan dalam operasi seksio sesarea di RSUD Kota Kendari adalah Ketorolak $30 \mathrm{mg}$ Intravena (IV), Tramadol 100 mg IV, dan Dexketoprofen 50 mg IV. Ketorolak IV memiliki waktu paruh 4VAS T6. Tramadol $100 \mathrm{mg}$ IV memiliki waktu paruh 5-7 jam., dan Dexketoprofen 50 mg IV memiliki durasi efek 8 jam (Katzung dkk., 2014; Sulistyowati, 2009).
Penelitian mengenai penilaian intensitas nyeri terhadap penggunaan analgetik pada pasien pasca seksio sesarea di Sulawesi Tenggara sendiri belum pernah dilakukan, sehingga peneliti tertarik dalam mengetahui nilai VAS pada penggunaan analgetik pasca seksio sesarea di RSUD Kota Kendari.

\section{METODE PENELITIAN}

Metode penelitian ini menggunakan metode observasional analitik dengan desain cross sectional. Penelitian ini dilaksanakan pada bulan Desember 2017 - Januari 2018 di RSUD Kota Kendari. Teknik pengambilan sampel pada penelitian ini adalah purposive sampling dengan pengambilan total sampel menggunakan the rule of thumb sebanyak 32 sampel.

Peneliti menggunakan uji distribusi normal dengan uji Shapiro-wilk (sig. <0,05), sehingga peneliti menggunakan uji Non Parametrik Kruskal-Wallis. Variabel bermakna jika p-value $<0,05$ dalam mengetahui hubungan variabel VAS terhadap variabel jenis analgetik di RSUD Kota Kendari. Penelitian ini telah mendapatkan persetujuan dari Komisi Etik Penelitian Kesehatan Lembaga Penelitian dan Pengabdian pada Masyarakat Universitas Halu Oleo, dengan nomor surat: 2054/UN29.20/PPM/2017.

\section{HASIL}

Tabel 1 menyajikan data mengenai proporsi umur, data VAS, data MAP dan data Nadi pada pasien pasca operasi seksio sesarea di RSUD Kota Kendari. Distribusi variabel menurut umur pada sampel pasca seksio sesarea di RSUD Kota Kendari berdasarkan rekam medik sampel bahwa dari 30 sampel, 
kelompok umur 20 - 35 tahun berjumlah 28 berjumlah 2 sampel $(6,7 \%)$. sampel $(93,3 \%)$ dan kelompok $>35$ tahun

Tabel 1. Proporsi Umur

\begin{tabular}{lcc}
\hline Kategori Umur & N & \% \\
\hline $20-35$ Tahun & 28 & 93,3 \\
$>35$ Tahun & 2 & 6,7 \\
Total & 30 & 100,0 \\
\hline
\end{tabular}

Sumber : Data Primer, 2018

Tabel 2 menunjukkan distribusi umur menurut kelompok analgetik Ketorolak, Tramadol dan Dexketoprofen. Kelompok Ketorolak menunjukkan 10 sampel diantaranya umur 21 tahun terdapat 1 sampel $(10 \%)$, umur 25 tahun terdapat 2 sampel (20\%), umur 28 tahun terdapat 1 sampel (10\%), umur 29 tahun terdapat 1 sampel $(10 \%)$, umur 30 tahun terdapat 1 sampel $(10 \%)$, umur 35 tahun terdapat 1 sampel (10\%), dan umur 36 tahun terdapat 1 sampel (10\%). Pada kelompok tramadol menunjukkan 10 sampel diantaranya umur 21 tahun terdapat 1 sampel (10\%), umur 26 tahun terdapat 1 sampel $(10 \%)$, umur 27 tahun terdapat 1 sampel $(10 \%)$, umur 28 tahun terdapat 3 sampel $(30 \%)$, umur 31 tahun terdapat 1 sampel (10\%), dan umur 36 tahun terdapat 2 sampel $(20 \%)$. Sedangkan pada kelompok Dexketoprofen menunjukkan 10 sampel diantaranya umur 22 tahun terdapat 1 sampel (10\%), umur 25 tahun terdapat 4 sampel $(40 \%)$, umur 26 tahun terdapat 1 sampel $(10 \%)$, umur 30 tahun terdapat 1 sampel $(10 \%)$, umur 34 tahun terdapat 1 sampel $(10 \%)$ dan umur 35 tahun terdapat 2 sampel (20\%).

Peneliti telah melakukan uji validitas dan reabilitas pada distribusi umur sampel terhadap ketiga kelompok analgetik yakni kelompok Ketorolak, kelompok Tramadol dan kelompok Dexketoprofen. Hasil yang didapatkan adalah 0,510. Nilai uji validitas dan reabilitas valid jika p-value $>0,05$, sehingga perbedaan umur diantara ketiga kelompok analgetik valid untuk dibandingkan.

Data pada Tabel 3 menunjukkan nilai rerata VAS terhadap analgesia di RSUD Kota Kendari. Pada VAS T2, nilai rerata yang tertinggi adalah Tramadol yakni 19,10. dan yang terendah adalah Ketorolak yakni 12,15. Pada kelompok VAS T4, nilai rerata yang tertinggi ditunjukkan pada kelompok Tramadol yakni 18,60 dan yang terendah adalah Dexketoprofen yakni 13,85.Sedangkan pada VAS T6, nilai rerata tertinggi pada kelompok Dexketoprofen yakni 16,95 dan yang terendah adalah kelompok Ketorolak yakni 13,75.

Tabel 4 menunjukkan kelompok Ketorolak $(n=10)$, VAS T2 terdapat 2 sampel (20\%) dengan intensitas nyeri sedang dan terdapat 8 sampel (80\%) dengan nyeri ringan. Pada VAS T4, terdapat 5 sampel (50\%) dengan intensitas nyeri sedang dan terdapat 5 sampel (50\%) dengan nyeri ringan. Sedangkan pada VAS T6, nyeri sedang terdapat 6 sampel $(60 \%)$ dan nyeri ringan terdapat 4 sampel (40\%).

Kelompok Tramadol $(n=10)$ pada VAS T2 menunjukkan 1 sampel (10\%) nyeri sedang dan 9 sampel (90\%) nyeri ringan.Pada VAS T4 nyeri sedang terdapat 7 sampel $(70 \%)$ dan nyeri ringan terdapat 3 sampel (30\%).Sedangkan pada VAS T6 intensitas nyeri sedang sebanyak 8 sampel 
$(80 \%)$ dan nyeri ringan sebanyak 2 sampel

\begin{tabular}{|c|c|c|c|}
\hline & Jenis Analgetik & $\mathrm{N}$ & Rerata \\
\hline \multirow[t]{4}{*}{ VAS 2} & Ketorolak & 10 & 12,15 \\
\hline & Tramadol & 10 & 19,10 \\
\hline & Dexketoprofen & 10 & 15,25 \\
\hline & Total & 30 & \\
\hline \multirow[t]{4}{*}{ VAS 4} & Ketorolak & 10 & 14,05 \\
\hline & Tramadol & 10 & 18,60 \\
\hline & Dexketoprofen & 10 & 13,85 \\
\hline & Total & 30 & \\
\hline \multirow[t]{4}{*}{ VAS 6} & Ketorolak & 10 & 13,75 \\
\hline & Tramadol & 10 & 15,80 \\
\hline & Dexketoprofen & 10 & 16,95 \\
\hline & Total & 30 & \\
\hline
\end{tabular}

$(20 \%)$.

Tabel 2. Distribusi Umur menurut Kelompok Analgetik

Sumber : Data Primer, 2018

Tabel 3. Distribusi Rerata VAS terhadap Analgetik di RSUD Kota Kendari

\begin{tabular}{llllllllllll}
\hline Kelompok Analgesik & \multicolumn{10}{c}{ Umur } & \multicolumn{1}{c}{ Rerata } \\
\hline Ketorolak & 28 & 32 & 35 & 30 & 25 & 25 & 27 & 36 & 29 & 21 & $\mathbf{2 8 , 8}$ \\
Tramadol & 28 & 28 & 28 & 36 & 36 & 31 & 27 & 31 & 21 & 26 & $\mathbf{2 9 , 2}$ \\
Dexketoprofen & 25 & 34 & 25 & 25 & 35 & 30 & 26 & 35 & 22 & 25 & $\mathbf{2 8 , 2}$ \\
\hline
\end{tabular}

Sumber : Data Primer, 2018

Kelompok Dexketoprofen $(\mathrm{n}=10)$ dengan intensitas nyeri ringan sebanyak 10 sampel (100\%) pada VAS T2.VAS T4 menujunjukkan nyeri sedang 5 sampel $(50 \%)$ dan nyeri ringan 5 sampel (50\%).Sedangkan pada VAS T6 intensitas nyeri sedang sebanyak 8 sampel $(80 \%)$ dan nyeri ringan sebanyak 2 sampel $(20 \%)$.

Pada nilai VAS T2 menunjukkan bahwa pada kelompok Ketorolak nilai VAS 1 terdapat 2 sampel $(6 \%)$, nilai VAS 2 terdapat 5 sampel (16\%), nilai VAS 3 terdapat 2 pasien (6\%), dan nilai VAS 4 terdapat 1 sampel (3\%). Pada kelompok Tramadol, menunjukkan nilai VAS 1 terdapat 1 sampel $(3 \%)$, nilai VAS 2 terdapat 1 sampel (3\%), nilsi VAS 3 terdapat 7 pasien $(23 \%)$ dan nilai VAS 4 terdapat 1 pasien $(3 \%)$. Sedangkan pada kelompok Dexketoprofen menunjukkan nilai VAS $1(0 \%)$, nilai VAS 2 terdapat 5 pasien, nilai VAS 3 terdapat 5 pasien dan nilai VAS 4 terdapat 0 sampel $(0 \%)$.

Tabel 4. Distribusi Kategotrik Nilai VAS terhadap kelompok Analgetik

\begin{tabular}{llllllll}
\hline & \multicolumn{9}{c}{ VAS T2 } & \multicolumn{2}{c}{ VAS T4 } & \multicolumn{2}{c}{ VAS T6 } & \multirow{2}{*}{ Total } \\
\cline { 2 - 7 } & Nyeri & Nyeri & Nyeri & Nyeri & Nyeri & Nyeri & \\
Jenis Analgesia & Sedang & Ringan & Sedang & Ringan & Sedang & Ringan & \\
\hline Ketorolak & 2 & 8 & 5 & 5 & 6 & 4 & 30 \\
Tramadol & 1 & 9 & 7 & 3 & 8 & 2 & 30 \\
Dexketoprofen & 0 & 10 & 5 & 5 & 8 & 2 & 30 \\
\hline
\end{tabular}


Sumber : Data Primer, 2018

Tabel 5. Distribusi Numerik Nilai VAS terhadap kelompok Analgetik

\begin{tabular}{lccccccccccc}
\hline & \multicolumn{1}{c}{ VAS } \\
\hline Kelompok Analgetik & 1 & 2 & 3 & 4 & 2 & 3 & 4 & 5 & 3 & 4 & 5 \\
\hline Ketorolak & 2 & 5 & 2 & 1 & 1 & 4 & 3 & 2 & 3 & 4 & 3 \\
Tramadol & 1 & 1 & 7 & 1 & 0 & 3 & 3 & 4 & 2 & 4 & 4 \\
Dexketoprofen & 0 & 5 & 5 & 0 & 0 & 5 & 4 & 1 & 2 & 3 & 5 \\
\hline Total & 3 & 11 & 14 & 2 & 1 & 12 & 10 & 7 & 7 & 11 & 12 \\
\hline
\end{tabular}

Sumber : Data Primer, 2018

Pada nilai VAS T4 menunjukkan bahwa kelompok Ketorolak dengan nilai VAS 2 terdapat 1 sampel (3\%), nilai VAS 3 terdapat 4 sampel (13\%), nilai VAS 4 terdapat 3 sampel (10\%), nilai VAS 5 terdapat 2 sampel (6\%). Pada kelompok Tramadol menunjukkan nilai VAS 3 terdapat 3 sampel (10\%), nilai VAS 4 terdapat 3 pasien $(10 \%)$ dan nilai VAS 5 terdapat 4 sampel (13\%). Sedangkan pada kelompok Dexketoprofen menunjukkan nilai VAS 3 terdapat 5 sampel (16\%), nilai
VAS 4 terdapat 4 sampel (13\%), dan nilai VAS 5 terdapat 1 sampel (3\%).Pada nilai VAS T6 menunjukkan pada kelompok Ketorolak dengan nilai VAS 3 terdapat 3 sampel (10\%),

Tabel 6 menunjukkan pada kelompok Ketorolak, terjadi peningkatan nilai TAR T2 sampai dengan TAR T6. Nilai rerata TAR T2 adalah 85,98, nilai rerata TAR T4 adalah 86,80 , dan nilai rerata TAR T6 adalah 94,35.

Tabel 6. Distribusi Rerata Nilai TAR terhadap Kelompok Analgetik

\begin{tabular}{llrrr}
\hline Jenis Analgetik & & TAR 2 & TAR 4 & \multicolumn{1}{c}{ TAR 6 } \\
\hline Ketorolak & Rerata & 85,98 & 86,80 & 94,35 \\
& $\mathrm{n}$ & 10 & 10 & 10 \\
& Standar Deviasi & 10,777 & 15,117 & 13,037 \\
\hline Tramadol & Rerata & 91,64 & 90,63 & 94,32 \\
& $\mathrm{n}$ & 10 & 10 & 10 \\
& Standar Deviasi & 10,582 & 10,734 & 10,428 \\
\hline \multirow{3}{*}{ Dexketoprofen } & & & & \\
& Rerata & 84,28 & 87,29 & 89,65 \\
& $\mathrm{n}$ & 10 & 10 & 10 \\
& Standar Deviasi & 7,377 & 8,862 & 7,767 \\
\hline Total & Rerata & 87,30 & 88,24 & 92,77 \\
& $\mathrm{n}$ & 30 & 30 & 30 \\
& Standar Deviasi & 9,896 & 11,578 & 10,501 \\
\hline
\end{tabular}

Sumber : Data Primer, 2018 
Tabel 7.Distribusi Rerata Nilai Nadi terhadap Kelompok Analgetik

\begin{tabular}{llrrr}
\hline Jenis Analgetik & & Nadi T2 & Nadi T4 & Nadi T6 \\
\hline Ketorolak & Rerata & 78,20 & 83,80 & 83,30 \\
& $\mathrm{n}$ & 10 & 10 & 10 \\
& Standar Deviasi & 13,037 & 17,593 & 15,326 \\
\hline Tramadol & Rerata & 81,60 & 88,40 & 90,40 \\
& $\mathrm{~N}$ & 10 & 10 & 10 \\
& Standar Deviasi & 15,255 & 13,842 & 12,020 \\
\hline \multirow{3}{*}{ Dexketoprofen } & & & & \\
& Rerata & 77,00 & 79,90 & 83,70 \\
& $\mathrm{~N}$ & 10 & 10 & 10 \\
& Standar Deviasi & 13,250 & 9,231 & 8,603 \\
\hline Total & Rerata & 78,93 & 84,03 & 85,80 \\
& $\mathrm{~N}$ & 30 & 30 & 30 \\
& Standar Deviasi & 13,542 & 13,944 & 12,316 \\
\hline
\end{tabular}

Sumber :Data Primer, 2018

Berbeda halnya pada kelompok Tramadol, terjadi penurunan nilai TAR pada T4 kemudian meningkat pada T6. Nilai rerata TAR T2 adalah 91,64, nilai rerata TAR T4 adalah 90,63 dan nilai rerata TAR T6 adalah 94,32. Kelompok Dexketoprofen terjadi peningkatan nilai rerata TAR dari T2 sampai dengan T6. Nilai rerata TAR T2 adalah 84,28, nilai rerata TAR T4 adalah 87,29 dan nilai rerata TAR T6 adalah 89,65.

Pada Tabel 7 menunjukkan pada Kelompok Ketorolak terjadi peningkatan rerata Nadi T2 ke T4 kemudian menurun pada T6. Nilai rerata nadi pada T2 adalah 78,20 , nilai rerata nadi pada $\mathrm{T} 4$ adalah 83,80 dan nilai rerata pada T6 adalah 83,30 .

Kelompok Tramadol menunjukkan terjadi peningkatan rerata Nadi dari T2 sampai dengan T6. Nilai rerata Nadi pada T2 adalah 81,60, nilai rerata Nadi pada T4 adalah 88,40 dan nilai rerata Nadi T6 adalah 90,40.

Kelompok Dexketoprofen menunjukkan terjadi peningkatan rerata Nadi dari T2 sampai dengan T6. Nilai rerata Nadi T2 adalah 77,00, nilai rerata Nadi T4 adalah 79,90 dan nilai rerata Nadi T6 adalah 83,70.

\section{Analisis Bivariat}

Analisis bivariat bertujuan untuk menguraikan hubungan antara variabel independen dan variabel dependen yaitu nilai VAS terhadap pemberian analgetik pada 30 sampel $(n=10)$ pasca operasi seksio sesarea di RSUD Kota Kendari. Jumlah sampel dibawah $\mathrm{n}=<50$ menggunakan analisis distribusi normal Shapiro-wilk sehingga didapatkan nilai signifikasi $<5 \%$ atau $<0,05$ yang menggambarkan data tidak terdistribusi normal. 
Tabel 8. Hasil Uji Analisis Kruskal Wallis Nilai VAS terhadap penggunaan Analgetik di RSUD Kota Kendari

\begin{tabular}{lccc}
\hline & VAS T2 & VAS T4 & VAS T6 \\
\hline Chi-Square & 3,686 & 2,099 & 0,775 \\
Df & 2 & 2 & 2 \\
Asymp. Sig. & 0,158 & 0,350 & 0,679 \\
a. Kruskal Wallis Test & & \\
b. Grup Variabel: Jenis Analgetik & & & \\
\hline Sumber : Data Primer, 2018 & &
\end{tabular}

Sumber : Data Primer, 2018

Peneliti menggunakan aplikasi komputer SPSS 16.0, dengan tingkat kemaknaan 95\% $(\alpha<5 \%)$ menggunakan uji non parametrik Kruskal-Wallis dengan syarat data tidak terdistribusi normal. Uji Kruskal-Wallis digunakan pada analisis komparatif untuk menguji lebih dari 2 variabel independen dengan ketentuan jumlah sampel tidak sama dan antara ketiga sampel tidak saling mempengaruhi. Kriteria pengujian diambil berdasarkan nilai probabilitas (Sig.) dimana jika nilainya $<0,05$ maka $\mathrm{Ha}$ diterima (Sopiyudin, 2013).

Tabel 8 menunjukkan nilai signifikasi pada VAS T2 pasca operasi adalah 3,686, nilai signifikasi VAS T4 pasca operasi adalah 2,099, dan nilai signifikasi VAS T6 pasca operasi adalah 0,775. Ketiga nilai VAS menunjukkan nilai signifikasi $>0,05$. Hal ini menggambarkan nilai VAS T2, nilai VAS T4 dan VAS T6 tidak berbeda bermakna.

\section{PEMBAHASAN}

\section{Distribusi Umur}

Usaha pengontrolan variabel yang dilakukan peneliti antara lain mengendalikan umur sampel. Faktor umur mempengaruhi intensitas nyeri.Umur ibu yang lebih muda memiliki sensori nyeri yang lebih intens dibandingkan dengan ibu yang memiliki umur yang lebih tua.Umur muda cenderung dikaitkan dengan kondisi psikologis yang masih labil yang memicu terjadinya kecemasan sehingga nyeri dirasakan lebih kuat (Umboh, 2015). Sehingga peneliti membatasi umur sampel 18-36 tahun. Presentasi umur pada sampel yang menjalani operasi seksio sesarea di RSUD Kota Kendari menunjukkan bahwa dari 30 sampel, kelompok umur 20 - 35 tahun berjumlah 28 sampel $(93,3 \%)$ dan kelompok $>35$ tahun berjumlah 2 sampel (6,7\%). Angka tertinggi ditunjukkan pada kelompok umur remaja akhir sebanyak $(93,3 \%)$ yang merupakan umur reproduktif yang optimal bagi ibu hamil untuk melahirkan.Umur yang ideal bagi ibu untuk melahirkan adalah 20 sampai 30 tahun karena dalam periode dengan resiko komplikasi medis yang paling rendah (Prawirohardjo, 2009).

Umur ibu menentukan kesehatan maternal dan sangat berhubungan erat dengan kondisi kehamilan, persalinan dan 
nifas serta kesehatan bayinya. Usia ibu hamil yang terlalu muda $<20$ tahun, keadaan tubuhnya belum siap menghadapi kehamilan, persalinan, nifas dan merawat bayinya. Sedangkan pada ibu yang usianya $>35$ tahun mengahadapi risiko seperti kelainan bawaan dan penyulit karena jaringan otot rahim yang kurang baik dalam menerima janin (Prawirohardjo, 2009).

Penelitian memperlihatkan bahwa risiko seksio sesarea lebih tinggi diantara wanita yang lebih tua yaitu 2-3 kali lebih banyak melakukan seksio sesarea dibandingkan yang berusia 20 tahun. Dua indikasi yang lebih sering dialami wanita dewasa akhir yakni persalinan macet dan kelainan letak janin (Andriani, 2012).

\section{Analisis Nilai VAS terhadap Analgetik di RSUD Kota Kendari}

Analgetik yang digunakan di RSUD Kota Kendari sebagai analgetik pasca operasi seksio sesarea antara lain Ketorolak $30 \mathrm{mg}$ IV, Tramadol $100 \mathrm{mg}$ IV dan Dexketoprofen 50 mg IV.

Ketorolak bekerja sangat selektif pada penghambatan langsung COX-1, sehingga penggunaan Ketorolak tidak dianjurkan lebih dari 5 hari karena dapat memperpanjang agregasi trombosit yang menyebabkan perdarahan. Dengan penghambatan COX-1 maka tidak terbentuknya prostaglandin dan antihistamin sehingga tidak terjadi penjalaran nyeri secara perifer. Ketika tubuh mendapatkan stimuli fisiologis maupun patologis maka AA akan dilepaskan dari membran fosfalipid dan diubah menjadi prostanoid termasuk prostaglandin dan tromboksan. Pada siklus AMP, sel darah putih menghambat pengeluaran prostaglandin, leukotrin, bradikinin, histamin sehingga menurunkan intensitas nyeri (Lewis dan Han, 1997).

Lewis dan Han

mengemukakan bahwa Tramadol adalah suatu analog kodein sintetik yang merupakan suatu agonis reseptor opioid $\mu$ yang lemah. Sebagian efek analgesiknya dihasilkan oleh penghambatan ambilan norepinefrin dan serotonin dari sistem aferen. Tramadol sama efektifnya dengan opioid lainnya dalam penanganan nyeri ringan sampai sedang. Namun Tramadol tidak menghambat proses inflamasi yang terjadi pada perlukaan. Sehingga masih terdapat prostanoid yang akan dikonversi menjadi prostaglandin, bradikinin, dan antihistamin lainnya yang merupakan mediator nyeri disekitar insisi luka operasi. Tramadol memerlukan kombinasi analgetik lainnya Sedangkan Deksketoprofen memiliki kemampuan penghambatan enzim silooksigenase lebih kuat dimana deksketoprofen bersifat dual COX inhibitor yang menghambat enzim COX-1 dan COX-2 sama besarnya. ((Sulistyowati, 2009; Ian Tanu, 2012; Riccioti dan FitzGerald, 2011).

Pada VAS T2, nilai rerata yang tertinggi adalah Tramadol yakni 19,10. dan yang terendah adalah Ketorolak yakni 12,15. Dengan uji Kruskal-Wallis, nilai 
rerata ketiga kelompok menunjukkan probabilitas $>0,05$ sehingga dapat dikatakan perbedaan ketiga kelompok analgetik tidak berbeda bermakna.

Kelompok analgetik pada VAS T4 pasca operasi, nilai rerata yang tertinggi adalah Tramadol yakni 18,60 dan yang terendah adalah Dexketoprofen yakni 13,15. Dengan uji Kruskal-Wallis nilai rerata ketiga kelompok menunjukkan probabilitas $>0,05$ sehingga dapat dikatakan perbedaan ketiga kelompok analgetik tidak berbeda bermakna.

VAS pada VAS T6 pasca operasi menunjukkan nilai rerata yang tertinggi adalah Dexketoprofen yakni 16,95 dan yang terendah adalah Ketorolak yakni 13,75. Dengan uji Kruskal-Wallis nilai rerata ketiga kelompok menunjukkan probabilitas $>0,05$ sehingga dapat dikatakan perbedaan ketiga kelompok analgetik tidak berbeda bermakna.

Penelitian ini sejalan dengan penelitian yang dilakukan oleh Yosieto (2015) yang membandingkan efektivitas analgesia Ketorolak dan Tramadol tidak terdapat perbedaan bermakna. Lain halnya dengan penelitian yang dilakukan oleh Pritaningrum (2010) yang membandingkan Ketorolak dengan Dexketoprofen. Penelitian Pritaningrum (2010) menunjukkan bahwa Dexketoprofen lebih unggul dibandingkan dengan Ketorolak. Penelitian ini juga tidak sejalan dengan penelitian Ong dkk. (2004) yang menyatakan bahwa Ketorolak lebih efektif dibandingkan dengan Tramadol.

\section{Analisis Nilai TAR dan Nadi terhadap penggunaan analgetik pada pasien pasca seksio sesarea di RSUD Kota Kendari}

TAR dan Nadi merupakan bagian dari pengukuran perubahan hemodinamik pada pasien pasca operasi dalam mendukung nilai VAS. Respon neurologik yang terukur yang disebkan oleh stimulasi simpatis yang disebut sebagai hiperaktivitas autonom.Perubahanperubahan ini mencakup takikardia, takipnea, meningkatnya aliran darah perifer, meningkatnya tekanan darah (baik sistol maupun diastolik), dan dibebaskannya katekolamin-suatu respon stres yang khas (Ekawari, 2015).

Pada penelitian Pritaningrum (2010) menyatakan bahwa pengggunaan Ketorolak terdapat peningkatan laju diastol, nadi dan pernafasan dari awal pemberian hingga pasca operasi namun dalam batas normal. Hal ini sesuai dengan penelitian yang dilakukan, dimana pada Kelompok Ketorolak didapatkan peningkatan nilai rerata T2 TAR dan Nadi sampai dengan T6. Pada kelompok Tramadol hasil yang didapatkan adalah terjadi penurunan pada T4 kemudian meningkat kembali pada T6 dengan perbedaan rerata 0,005 . Perbedaan penurunan TAR ini sangat kecil. Hal ini didukung oleh penelitian Yosieto (2015) menemukan bahwa pada pasien yang diberikan Tramadol IV tidak terdapat perbedaan bermakna pada tekanan darah, sistolik dan sistolik. Hal ini karena Tramadol bekerja sentral pada neurotransmitter noradrenergik dan serotonergik dengan meningkatkan 
aktivitas saraf penghambat monoaminergik menyebabkan terhambatnya transmisi nyeri sehingga tekanan darah maupun nadi tidak akan meningkat. Sedangkan pada kelompok Dexketoprofen menunjukkan terjadinya peningkatan rerata TAR dan nadi pada T2 hingga T6. Penelitian ini sejalan dengan penelitian Sulistyowati (2009) yang menyatakan bahwa rerata nilai sistolik dan diastolik terjadi peningkatan namun tidak bermakna $p$-value $>0,05$.

\section{SIMPULAN}

Simpulan penelitian ini adalah terdapat perbandingan nilai rerata VAS T2, VAS T4 dan VAS T6. Ketorolak 30 mg memiliki nilai rerata VAS T2 terendah diantara kelompok analgetik lainnya yakni 12,15, Dexketoprofen $50 \mathrm{mg}$ memiliki nilai rerata VAS T4 terendah diantara kelompok analgetik lainnya yakni 13,85 , Ketorolak $30 \mathrm{mg}$ memiliki nilai rerata VAS T6 terendah diantara kelompok analgetik lainnya yakni 13,75. Namun, secara statistik tidak ada perbedaan bermakna terhadap penggunaan analgetik Ketorolak $30 \mathrm{mg}$ IV, Tramadol $100 \mathrm{mg}$ IV, dan Dexketoprofen $50 \mathrm{mg}$ IV pada pasien pasca operasi seksio sesarea di RSUD Kota Kendari.

\section{SARAN}

Peneliti mengusulkan penggunaan analgetik tunggal Ketorolak $30 \mathrm{mg}$ sebagai pemberian analgetik utama pasca operasi seksio sesarea kemudian analgetik Dexketoprofen $50 \mathrm{mg}$ dan Tramadol 100 mg sebagai analgetik alternatif. Bagi peneliti selanjutnya, melakukan penelitian mengenai analgetik multimodal pada sampel pasca operasi seksio sesarea maupun pada jenis operasi lainnya. Menjalin koordinasi yang baik antara peneliti dengan tenaga kesehatan terkait dalam hal ini dokter, perawat, bidan, dan mahasiswa di RSUD Kota Kendari.

\section{DAFTAR PUSTAKA}

Agroff, E., McCleane, G. 2010. Pain management SECRETS $3^{\text {rd }}$ edition. Mosby Elsevier. China.

Andriani, D. 2012. Faktor-Faktor yang Mempengaruhi Tindakan Seksio Sesarea di Rumah Sakit Umum Daerah Kabupaten Dompu Tahun 2010. Skripsi. Fakultas Kesehatan Masyarakat Program Sarjana Kesehatan Masyarakat Pemintatan Kebidanan Komunitas Universitas Indonesia. Depok.

Ekawari, K., Lalenoh, D., Kumaat, L. 2015. Profil Nyeri dan Perubahan Hemodinamik Pasca Bedah Perut Bawah dengan Ketorolak $30 \mathrm{mg}$ Inttravena. Journal e-Clinic (eCl) 3 (1) : 434-439.

Ismail, S., Afshan, G., Monem, A., Ahmed, Aliya. 2012. Postoperative Analgesia Following Caesarean Section: Intravenous Patient Controlled Analgesia versus Conventional Continuous Infusion. Open Journal of Anesthesiology 2: 120-126. 
Joshi G.P., Ogunnaike B.O. 2005. Concequences of inadequate postoperative pain relief and chronic persistent postoperative pain. Anesthesiology Clin N Am 23: 21-36.

Katzung, G.B. 2014. Farmakologi Dasar dan Klinik Edisi 12 Vol 2. EGC. Jakarta.

Lewis, K.S dan Han, N.H. 1997. Tramadol: a new centrally acting analgesic. Am J Health Syst Pharm. 54 (6): 43-52.

Ong, K.S., Seymour, R.A., Chen, F.G., Ho, V.C. 2004. Preoperative ketorolac has a preemptive effect for postoperative third molar surgical pain. Int J Oral Maxillo fac Surg. 33: 771-776.

Prawirohardjo, S. 2009. Ilmu Kebidanan Sarwono Prawirohardjo. Bina Pustaka Sarwono Prawirohardjo. Jakarta.

Price, A.S., Willson, L.M. 2006. Patofisiologi: Konsep Klinis dan Proses-Proses Penyakit. Vol 2. EGC. Jakarta

Pritaningrum, F. 2010. Perbedaan Skor Visual Analogue Scale antara Ketorolak dan Deksketoprofen pada Pasien Pasca Bedah. Skripsi. Program Studi Pendidikan Dokter Universitas Diponegoro. Semarang.

Riccioti, E., FitzGerald, G.A. 2011. Prostaglandin and Inflammation.
Journal of The American Heart Association 31: 986-1000.

Salfitriani, I., Nasution S.S. 2012. Determian Persalinan Seksio Sesarea Tanpa Indikasi Medis di RSU Bunda Thamrin Medan. $J$ Keperawatan Klin 1 (1) : 7-12.

Sofian, Amru. 2013. Rustam Mochtar Sinopsis Obsetri: Obsetri Operatif, Obsetri Sosial. Edisi Ketiga. Jilid 2. EGC. Jakarta.

Sopiyudin, M D. 2013.Statistik Untuk Kedokteran dan Kesehatan Edisi 5. Salemba Medika. Jakarta.

Sulistyowati, R. 2009. Perbedaan Pengaruh Pemberian Ketorolak dan Deksketoprofen sebagai Analgesia pasca Bedah terhadap Agregasi Trombosit. Tesis. Program Pascasarjana Program Pendidikan Dokter Spesialis Ilmu Anastesi. Universitas Diponegoro. Semarang.

Tanu, Ian. 2012. Farmakologi dan Terapi Edisi 5. Balai Penerbit FK UI. Jakarta Tanu, Ian. 2012. Farmakologi dan Terapi Edisi 5. Balai Penerbit FK UI. Jakarta.

Umboh, J. A. J. M. L. 2015. Hubungan antara Umur, Parietas, dan Pendampingan Suami dengan Intensitas Nyeri Persalinan Kala I Fase Aktif Deselarasi di Ruang Bersalin RSUD Prof. Dr. H. Aloei Saboe Kota Gorontalo Correlation between Age, Parity and Husband 
Assistance with Childbirt 5: 406413.

Yosieto, A., Kumaat, L., Posangi, I. 2015. Perbandingan Efektifitas Tramadol
100 mg IV Dengan Ketorolak 30 mg IV Terhadap Tingkat Nyeri Pasca Operasi Seksio Sesarea. Journal e-Clinic 3(1): 199-209. 